\title{
Cadmium burden and the risk and phenotype of prostate cancer Yi-Chun Chen ${ }^{\dagger 1,2}$, Yeong S Pu${ }^{\dagger 3}$, Hsi-Chin $\mathrm{Wu}^{4}$, Tony $\mathrm{T} \mathrm{Wu}^{5}$, Ming Kuen Lai ${ }^{1,3}$, Chun Y Yang ${ }^{6}$ and Fung-Chang Sung $* 2,4$
}

\begin{abstract}
Address: ${ }^{1}$ Department of Health Management, I-Shou University, Kaohsiung 824, Taiwan, ${ }^{2}$ Institute of Environmental Health, National Taiwan University, Taipei 100, Taiwan, ${ }^{3}$ Department of Urology, National Taiwan University Hospital, Taipei 100, Taiwan, ${ }^{4}$ Division of Urology and Institute of Environmental Health, China Medical University and Hospital, Taichung 404, Taiwan, ${ }^{5}$ Division of Urology, Kaohsiung Veterans General Hospital, Kaohsiung 813, Taiwan and ${ }^{6}$ Department of Public Health, Kaohsiung Medical University, Kaohsiung 807, Taiwan
\end{abstract}

Email: Yi-Chun Chen - kimi@isu.edu.tw; Yeong S Pu - yspu@ntu.edu.tw; Hsi-Chin Wu - wuhc@mail.cmu.edu.tw;

Tony T Wu - tonywu@isca.vghks.gov.tw; Ming Kuen Lai - mingkuen@ha.mc.mtu.edu.tw; Chun Y Yang - chunyuh@kmu.edu.tw; Fung-

Chang Sung* - fcsung@mail.cmu.edu.tw

* Corresponding author †Equal contributors

Published: 10 December 2009

BMC Cancer 2009, 9:429 doi:10.1 186/147|-2407-9-429

This article is available from: http://www.biomedcentral.com//47/-2407/9/429

(C) 2009 Chen et al; licensee BioMed Central Ltd.

This is an Open Access article distributed under the terms of the Creative Commons Attribution License (http://creativecommons.org/licenses/by/2.0), which permits unrestricted use, distribution, and reproduction in any medium, provided the original work is properly cited.
Received: 14 October 2008

Accepted: 10 December 2009

\begin{abstract}
Background: Studies on the association between prostate cancer and cadmium exposure have yielded conflicting results. This study explored cadmium burden on the risk and phenotype of prostate cancer in men with no evident environmental exposure.

Methods: Hospital-based $26 \mathrm{I}$ prostate cancer cases and 267 controls with benign diseases were recruited from four hospitals in Taiwan. Demographic, dietary and lifestyle data were collected by standardized questionnaires. Blood cadmium (BCd) and creatinine-adjusted urine cadmium (CAUCd) levels were measured for each participant. Statistical analyses measured the prostate cancer risk associated with BCd and CAUCd separately, controlling for age, smoking and institution. BCd and CAUCd levels within cases were compared in relation to the disease stage and the Gleason score.
\end{abstract}

Results: High family income, low beef intake, low dairy product consumption and positive family history were independently associated with the prostate carcinogenesis. There was no difference in BCd levels between cases and controls (median, 0.88 versus $0.87 \mu \mathrm{g} / \mathrm{l}, \mathrm{p}=0.45$ ). Cases had lower CAUCd levels than controls (median, 0.94 versus $1.40 \mu \mathrm{g} / \mathrm{g}$ creatinine, $\mathrm{p}=0.00 \mathrm{I}$ ). However, cases with higher BCd and CAUCd levels tended to be at more advanced stages and to have higher Gleason scores. The prostate cancer cases with Gleason scores of $\geq 8$ had an odds ratio of 2.89 (95\% confidence interval I.25-6.70), compared with patients with scores of 2-6.

Conclusion: Higher CAUCd and BCd levels may be associated with advanced cancer phenotypes, but there was only a tenuous association between cadmium and prostate cancer.

\section{Background}

The incidence and mortality rates of prostate cancer vary markedly among ethnic groups, being low in Asian and much higher in Western populations. Nonetheless, the incidence of the disease in Taiwan increased more than 3fold during the 1990s [1]. In addition to factors such as age, race and inherited predisposition, dietary factors, particularly fat, may also play important roles in prostate car- 
cinogenesis [2,3]. Various other environmental and occupational exposures have also been shown to be associated with prostate cancer. These include cadmium exposure, which has been investigated but with inconclusive results. The association of cadmium exposure with prostate cancer was reported by Potts in 1965 that three cadmium battery workers had died of the disease [4]. Several subsequent occupational and geographical studies gave conflicting results [5-11].

A geographical study in Spain showed that an area with elevated cadmium contamination also had a high population incidence of prostate cancer. However, the authors did not conclude that cadmium was the determining cause of prostate cancer; which probably has more to do with nature occurrence of the chemical than with human activity [9]. Occupational studies on cadmium exposure may be not general population representative because workers suffer much greater exposure than the general population. Similarly, ecological studies have been unable to address relevant confounding factors adequately. In these occupational and ecologic studies, no cadmium was measured in vivo to reflect the real human exposure and this may have led to conflicting results. To determine whether cadmium is an etiological or only a secondary factor in prostate carcinogenesis, measurement of cadmium levels in vivo may be helpful. Feustel et al. [12] measured the cadmium contents of prostate tissue and found elevated levels in malignant tissues. Vinceti et al. found that men in Italy with higher toenail cadmium are at higher risk for prostate cancer [13]. No study has investigated the cadmium burden using blood cadmium (BCd) and urine cadmium (UCd) levels among men with no occupational exposure. This study determined and compared the BCd and creatinine-adjusted urine cadmium (CAUCd) levels among prostate cancer patients with different disease phenotypes and in controls.

\section{Methods}

Subjects

Cases, which were histologically confirmed prostate adenocarcinoma, were recruited from four medical centers: two hospitals from northern, one from central and one from southern Taiwan. This recruitment plan was adopted in an attempt to represent the likely span of cadmium exposure across Taiwan as a whole. Controls were agematched male patients also from the same four hospitals who had received medical attention from the services of urology, family medicine, orthopedics, ophthalmology, otolaryngology and other services. Subjects acquired from the urology service were limited to those with inguinal hernia or urolithiasis. Subjects with other malignancies, hormonal disorders or benign prostatic diseases and men with the prostate specific antigen $>=4 \mathrm{ng} / \mathrm{ml}$ were excluded from the control group. This study was performed with the approval of the ethics committee.

\section{Data collection}

With physician approval, all participants recruited gave their informed consent prior to the study interview. Trained interviewers conducted personal interviews with all participants during hospital visits using standard questionnaires. The questionnaires covered information about socio-demographic characteristics, occupation history, tobacco and alcohol use, diet, physical activity, height and weight history, medical history, and family history of prostate cancer.

Using a food frequency questionnaire, both cases and controls reported dietary intake history from 10 years ago, determined by personal recall. The questionnaire was a validated instrument and had been used in previous studies $[14,15]$. It had been modified during the past few years to adapt it to the changing environment in our society. The questionnaire contained the most frequently consumed food items among Chinese, including poultry, pork, beef, egg, fish, seafood, diary products, vegetables and fruits, tofu, herbal preparations as food supplement, and eating out including banquets. Food consumption was reported at daily, weekly or monthly frequency. The questionnaire also asked information about smoking and some drink items including alcohol, coffee, soybean milk, tea, etc. Since the dietary history was determined using the semi-quantitative food frequency questionnaire, this version was validated with a Cronbach's alpha ranging from 0.75 to 0.84 .

Cancer stages and Gleason scores were extracted from medical records. Among the 261 cases, these data were available, respectively, for $220(84.3 \%)$ and $210(80.5 \%)$ cases. Cancer stages were recoded in Taiwan by the American Urology Association (AUA) System, and Tumor, Node and Metastasis (TNM) staging [1]. In this study, the cancer stage recorded by TNM staging system was transformed to the AUA system by a Urology specialist. Pathologists evaluated the architectural pattern of the glands of prostate tumors on the basis of histological examinations and gave scores representing the phenotype of prostate cancer. The score ranges from 2 to 10 , with 10 being associated with the worst phenotype or prognosis.

\section{Specimen collection and cadmium analysis}

Since cadmium has a biological half-life of decades in humans, blood and urine levels are considered fairly stable throughout the day. Therefore, single spot urine and blood samples were collected during scheduled appointments instead of at a standardized time during the day. The urine sample was collected in a sterile plastic cup and an aliquot of $10 \mathrm{ml}$ was transferred to a conical-bottomed 
cadmium-free plastic tube. Blood specimens of 2-3 ml were collected in pre-screened heparin tubes, also from lots verified to be free of cadmium contamination. Both urine and blood specimens were stored at $4{ }^{\circ} \mathrm{C}$ if analyzed within a week or at $-20^{\circ} \mathrm{C}$ if they were to be analyzed a week or more later. One $\mathrm{ml}$ of urine was used for creatinine determination in order to normalize the urine cadmium levels.

One hundred $\mu \mathrm{l}$ of blood plus $900 \mu \mathrm{l}$ of matrix modifier $\left(0.2 \%\right.$ nitric acid, $0.5 \%$ Triton ${ }^{\oplus} \mathrm{X}-100$ and $0.2 \%$ $\left.\left(\mathrm{NH}_{4}\right)_{2} \mathrm{HPO}_{4}\right)$ or $100 \mu \mathrm{l}$ of urine plus $200 \mu \mathrm{l}$ of matrix modifier $\left(25 \% \mathrm{NH}_{4} \mathrm{H}_{2} \mathrm{PO}_{4}\right.$ and $\left.1.25 \% \mathrm{Mg}\left(\mathrm{NO}_{3}\right)_{2}\right)$ were prepared for analyses [12]. Specimens, quality control samples, and standards admixed with matrix modifier were analyzed for cadmium contents using a Perkin-Elmer Model 5100 PC atomic absorption spectrometer with Zeeman background correction. For quality control, reference blood samples (NYCOMED PHARMA AS, Oslo, Norway) were used. Urinary cadmium analysis was verified every other month using the Inter-Laboratory Comparison Program, Le Centre de Toxicology du Québec (Sainte-Foy, QC, Canada). The recovery rates for spike tests were 100.7 $\pm 3.5 \%$ for urine analysis and $100.9 \pm 3.6 \%$ for blood analysis. The urine cadmium levels were adjusted for urinary creatinine content.

\section{Statistical analyses}

Contingency tables with Chi-square tests were used to examine the categorical variables to compare cases and controls. The associations with major exposures and covariates were examined. We selected several variables from three major categories - sociodemographics, lifestyle, and food consumption - as the covariates. BCd and CAUCd levels were examined by both parametric and non-parametric methods. Since neither level was normally distributed, medians BCd and CAUCd levels were compared between cases and controls using the Wilcoxon rank-sum test. Multivariate logistic regression models were used to estimate the contribution of other factors such as socioeconomic status, dietary habit and family history. We also compared the BCd and CAUCd levels by Kruskal-Wallis test with post hoc comparisons (Dunn test) in cases grouped according to tumor stages $(\mathrm{A}+\mathrm{B}, \mathrm{C}$, and $\mathrm{D})$ and Gleason scores $(2-6,7$, and $>=8)$ to check whether cadmium levels differed among graded malignant phenotypes. The analyses that estimated the odds ratios for association between cancer grade, by stage, and the Gleason score, and median levels of CAUCd ( $<=1.12 \mathrm{vs.}$ $>1.12 \mu \mathrm{g} / \mathrm{g}$ creatinine $)$ and BCd (<=0.87 vs. $>0.87 \mu \mathrm{g} / \mathrm{L})$ were based on available samples from cases. The significance level was taken as $\mathrm{p}<0.05$ in this study.

\section{Results}

A total of 261 cases (age: $72.1 \pm 6.8$ years) and 267 controls (age: $71.3 \pm 7.2$ years) were recruited. Comparisons of sociodemographics, lifestyle and food consumption showed no significant differences between cases and controls in body mass index, education, occupation, smoking, drinking or regular exercise. However, cases had a significantly higher family income $(p=0.001)$. Subjects with family histories of prostate cancer had a 3.4-fold greater risk than those without such histories $(p=0.02)$. Interestingly, cases tended to consume less beef $(p=0.04)$ and dairy products $(\mathrm{p}=0.046)$ but ate out more often ( $\mathrm{p}$ $=0.02$ ) than controls (data not shown).

Among the participants, 234 (89.7\%) cases and 248 $(92.9 \%)$ controls provided urine samples and 176 (67.4\%) cases and 147 (55.1\%) controls donated blood samples for cadmium measurements. Cases and controls who provided urine specimens were similar in mean ages; but among those who donated blood samples, the mean age was 1.8 years greater in cases than in controls (data not shown). Cases who provided either urine or blood specimens were wealthier and ate out frequently. There was no significant difference in education between cases and controls.

Figure 1 shows that there was no significant difference between cases and controls in median BCd levels $(0.88$ and $0.87 \mu \mathrm{g} / \mathrm{l}$, respectively). The median CAUCd levels were significantly lower in cases than in controls $(0.94$ and $1.40 \mu \mathrm{g} / \mathrm{g}$ creatinine, respectively, $\mathrm{p}=0.001$ by Wilcoxon rank-sum test).

Table 1 shows that after adjusting for age, smoking and the medical institution from which the subjects were recruited, high family income, low beef intake and low dairy product consumption remained significant independent factors predicting an elevated risk of prostate cancer when BCd was included in the model. In addition to these three factors, CAUCd and family history were also independent factors associated with the risk of prostate cancer when CAUCd was introduced into the model.

The distributions of tumor stages and Gleason scores were comparable among all four hospitals. The median BCd and CAUCd levels of cases with different tumor stages and Gleason scores are shown in Table 2. Both BCd and CAUCd levels tended to increase as tumor stage or Gleason score progressed. By the non-parametric KruskalWallis test, significant differences in both BCd and CAUCd levels were seen among patients with different Gleason scores ( $\mathrm{p}=0.013$ and 0.03 , respectively). There was a significant difference in CAUCd levels (but not BCd levels) among patients at different stages ( $p=0.043)$. Post hoc comparison showed that patients with a Gleason score of 7 had a higher BCd level than those with a score of 6 or less $(p=0.004)$. Similarly, patients with a Gleason score of 8 or more had a higher CAUCd level than those with a score of 6 or less $(p=0.03)$. Patients with stage $D$ 


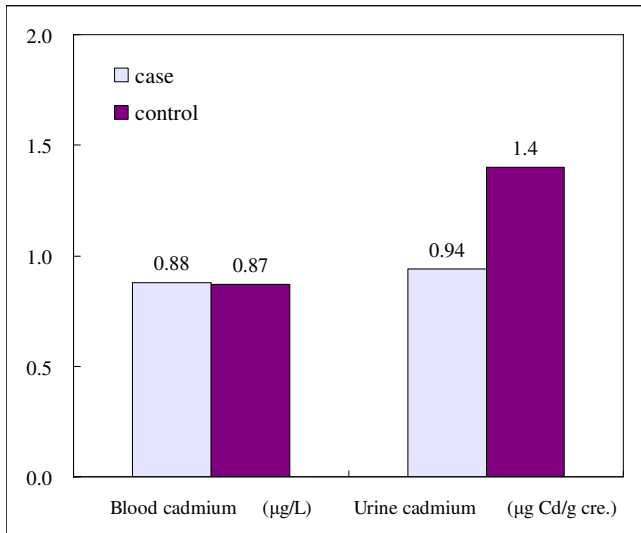

Figure I

Comparisons of median blood and urine cadmium levels between prostate cancer cases and controls.

disease had a higher CAUCd level than those with either stage $A+B(p=0.04)$ or $C(p=0.04)$. The data were also log-transformed and compared among stage groups and among Gleason score groups using ANOVA. Similar significance results were obtained.

Further data analyses showed that prostate cancer patients diagnosed at the advanced stage had greater odds ratios (OR) of having higher CAUCd and BCd, but this was not significant (Figure 2). Compared with patients with the Gleason scores of 2-6, the OR of prostate cancer being associated with CAUCd levels higher than $1.12 \mu \mathrm{g} \mathrm{Cd} / \mathrm{g}$ creatinine increased to 1.24 (95\% CI 0.64-2.42) for those with a score of 7, and to 2.89 (95\% CI 1.25-6.70) for those with a score of 8 ( $\mathrm{p}$ for trend 0.04 ). Higher Gleason scores were also associated with higher BCd.

\section{Discussion}

Population aging, lifestyle changes and increased screening have resulted in a rapid increase in both the incidence of and mortality from prostate cancer in low incidence Asian countries. In our previous study $[14,15]$ and the present study, we investigated the association between prostate cancer and socio-demographics, life style and dietary factors. In this study, we also investigated the association between the cadmium burden and prostate cancer risk, which has not previously been clearly delineated for men based on the measured BCD and CAUCd.

Animal and occupational studies have strongly suggested that cadmium is carcinogenic to the prostate $[5,6,8,16$ 19]. Waalkes et al. demonstrated a dose-response relationship in a rodent model when tumors were induced by injecting cadmium subcutaneously [19]. Animal experiments are usually conducted at the maximum tolerated doses or supra-normal levels of a certain toxin. Very few studies have focused on general human populations $[13,20,21]$.

A small-scale Nigerian epidemiological study showed that the plasma cadmium concentration is significantly higher in subjects with prostate cancer than in normal subjects or patients with benign prostatic hypertrophy [21]. There were only 12 cancer patients in that study all with locally advanced or metastatic disease. Vinceti et al. used toenail cadmium as an indicator of body burden and found a significant relationship between cadmium and prostate cancer; but, the statistical methods used were unstable, again because of the small sample size [13]. Another study using urinary cadmium as indicator showed a weak positive relationship between cadmium and prostate-specific antigen [20].

Occupational studies have also shown some evidences of elevated risks upon substantial exposure $[5,6,8]$. BCd levels normally range from 0.4 to $1.0 \mu \mathrm{g} / \mathrm{l}$ for nonsmokers and from 1.4 to $4.0 \mu \mathrm{g} / \mathrm{l}$ for smokers [22]. In the event of environmental or occupational exposure, BCd levels up to $10 \mu \mathrm{g} / \mathrm{L}$ may lead to renal dysfunction and/or osteopenia [23]. CAUCd levels normally average 0.35 and $>2 \mu \mathrm{g} / \mathrm{g}$ creatinine for nonsmokers and smokers, respectively [24]. For individuals with substantial occupational exposure, BCd may rise up to $50 \mu \mathrm{g} / \mathrm{L}$, and CAUCd up to $50 \mu \mathrm{g} / \mathrm{g}$ creatinine [25]. This suggests that a very high body burden of cadmium can occur in contaminated working environments, where the cadmium exposure is usually heavier than that incurred by smoking. However, it may not be appropriate to extrapolate data from rodent and occupational studies, in which high-dose exposures infer a relationship between cadmium burden and carcinogenesis in the general human population. This may explain why general observational studies, where no evident environmental exposure is present, have failed to reveal consistent results about the association of cadmium.

The present study demonstrated that men with prostate cancer have lower CAUCd levels and there is no significant difference in BCd level between cases and controls. However, patients with higher Gleason scores were more likely have higher cadmium burdens than patients with lower scores.

The primary sources of cadmium exposure for the general population are from smoking and contaminated food [26]. BCd primarily reflects recent exposure rather than whole body burden, while CAUCd is more indicative of long-term body burden with some contribution from recent exposure. Therefore, CAUCd seems a better marker than BCd for assessing the association between cadmium exposure and cancer risks $[17,27]$. Our data showed no 
Table I: Multiple logistic regression analyses for factors associated with prostate cancer *

\begin{tabular}{|c|c|c|c|c|c|}
\hline Variable & $\begin{array}{l}\text { Odds ratio } \\
\text { (95\% Cl) }\end{array}$ & $p$ & Variables & $\begin{array}{l}\text { Odds ratio } \\
\text { (95\% Cl) }\end{array}$ & $p$ \\
\hline Blood cadmium, $\mu g / l$ & & & Urine cadmium, $\mu \mathrm{g} C d / g$ creati & & \\
\hline$\leq 0.87$ & 1.0 & 0.24 & $\leq 1.12$ & 1.0 & 0.003 \\
\hline$>0.87$ & I.44 (0.78-2.64) & & $>1.12$ & $0.49(0.31-0.78)$ & \\
\hline Family income & & & Family income & & \\
\hline Median/low & 1.0 & 0.002 & Median/low & 1.0 & 0.002 \\
\hline High & $2.86(1.45-5.6 I)$ & & High & $2.25(1.35-3.73)$ & \\
\hline Beef & & & Beef & & \\
\hline Less & 1.0 & 0.041 & Less & 1.0 & 0.033 \\
\hline Frequent & $0.53(0.29-0.98)$ & & Frequent & $0.60(0.37-0.96)$ & \\
\hline Dairy products & & & Dairy products & & \\
\hline Less & 1.0 & 0.065 & Less & 1.0 & 0.056 \\
\hline Frequent & $0.49(0.23-1.04)$ & & Frequent & $0.58(0.33-1.01)$ & \\
\hline Eating out & & & Eating out & & \\
\hline Less & 1.0 & 0.309 & Less & $\mathrm{I} .0$ & 0.049 \\
\hline Frequent & $1.39(0.74-2.6 I)$ & & Frequent & $1.62(1.0-2.6)$ & \\
\hline Family history & & 0.095 & Family history & & 0.045 \\
\hline No & 1.0 & & No & 1.0 & \\
\hline Yes & $4.4 I(0.77-25.1)$ & & Yes & $3.47(1.03-11.7)$ & \\
\hline
\end{tabular}

* Analysis was done by controlling for subjects' ages, smoking status and medical institutions; $\mathrm{Cl}=$ confidence interval.

significant difference in BCd levels between cases and controls. To our surprise, subjects with higher CAUCd had a significantly lower risk for prostate cancer. This result contradicted our previous belief that UCd might parallel BCd in the association with the cancer risk. A possible explanation is that cadmium is carcinogenic to the prostate; prostate cancer may retain a significant amount of cadmium (nor related to the circulation levels) $[12,28]$ and allow only trace amounts to be excreted via the kidney, in contrast to a benign prostate that does not "absorb" cadmium and undergo malignant transformation. It may not matter how much cadmium enters the body in total. What matters is how much the prostate "traps" the cadmium and reacts to it. The change in CAUCd that we have observed merely reflects a balance in cadmium content between prostate tissue, blood and urine.

It may take decades for prostate epithelia to initiate and promote during carcinogenesis. It also takes years for the body cadmium burden to be eliminated after exposure. Once absorbed, cadmium is transported through the blood stream to various tissues. Cadmium in the liver and kidney accounts about $50 \%$ of the total body burden [26], as these organs synthesize large amounts of metallothionein, a metal-binding protein with a high affinity for cadmium. Cadmium is eliminated very slowly from the body. Its biological half-life of cadmium has been estimated as approximately 25-30 years in humans [29]. This long biological half-life may well set the stage for neoplastic transformation.

Our comparison of cadmium levels among cases with graded malignancies revealed potentially interesting results deserving careful interpretation and further study. In patients with prostate cancer, there was a trend towards higher tumor stages and worsening Gleason scores as the BCd or CAUCd levels increased, except that the association of BCd with tumor stages was not significant. Higher

Table 2: Median and 5-95th percentile range of blood and urine cadmium levels in prostate cancer patients by stage and Gleason score

\begin{tabular}{|c|c|c|c|c|c|c|c|}
\hline Stage & $\mathbf{N}$ & Median (5-95\%) & $\mathbf{p}^{*}$ & Gleason score & $\mathbf{N}$ & Median (5-95\%) & $\mathbf{p}^{*}$ \\
\hline \multicolumn{8}{|c|}{ Blood cadmium ( $\mu \mathrm{g} / \mathrm{l})$} \\
\hline$A+B$ & 56 & $0.85(0.12-3.52)$ & 0.285 & $2-6$ & 88 & $0.74(0.12-2.39)$ & 0.013 \\
\hline $\mathrm{C}$ & 34 & $0.89(0.11-2.62)$ & & 7 & 41 & $1.03(0.40-4.45)$ & \\
\hline $\mathrm{D}$ & 73 & $0.92(0.24-2.95)$ & & $\geq 8$ & 22 & $0.91(0.24-2.89)$ & \\
\hline \multicolumn{8}{|c|}{ Urine cadmium ( $\mu \mathrm{g} \mathrm{Cd} / \mathrm{g}$ creatinine) } \\
\hline$A+B$ & 72 & $0.76(0.10-3.95)$ & 0.043 & $2-6$ & 107 & $0.72(0.12-3.72)$ & 0.030 \\
\hline $\mathrm{C}$ & 43 & $0.74(0.14-2.91)$ & & 7 & 54 & $0.96(0.13-4.37)$ & \\
\hline $\mathrm{D}$ & 84 & $1.12(0.21-4.37)$ & & $\geq 8$ & 30 & $1.48(0.17-7.36)$ & \\
\hline
\end{tabular}

* By Kruskal-Wallis test 

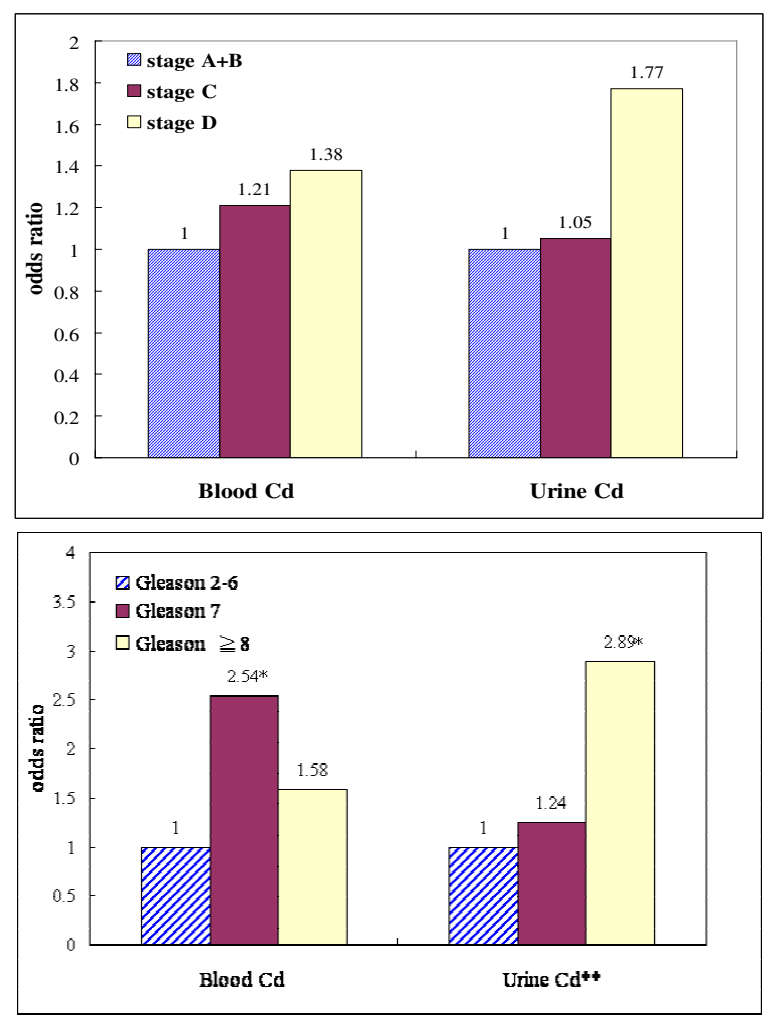

Figure 2

Odds ratio (OR) by stage (C, D vs $A+B)$ and Gleason score ( $\geq 7$ vs. 2-6) of association of prostate cancer with cadmium levels in urine and blood $\$$ (*p $<0.05$; **p for trend $=\mathbf{0 . 0 4}$ ). $\S$ Using the median level of cases as the cutoff value for risk determinations, $0.87 \mu \mathrm{g} / \mathrm{l}$ for blood cadmium and $1.12 \mu \mathrm{g} / \mathrm{g}$ creatinine for urine cadmium.

cadmium levels appeared to be associated more with the Gleason score than with tumor stage. CAUCd correlated significantly more strongly than BCd with the malignant phenotype of prostate cancer. The reason for this is unclear. It has been shown that levels of cadmium in prostate tissue are higher in more advanced diseases [12,28]. Patients with more advanced diseases may have first entrapped more cadmium into the prostate during carcinogenesis and then excreted more cadmium into the urine during disease progression and tumor necrosis than those with more localized diseases or low-grade tumors. However, as cadmium remains largely entrapped in the cancerous prostate, the CAUCd levels in cases are still lower than that in controls, especially in cases at earlier stages and with lower grades.

Although we believe that low urinary cadmium levels are associated with the entrapment of cadmium in the cancerous prostate, it is also possible that some people who are more sensitive to cadmium than others and thus may therefore develop cancer even at low exposure levels.

The strength of this study includes the recruitment of study subjects from medical centers distributed across all areas in Taiwan, which may have reduced the bias from patient selection, environmental exposure or dietary differences. This study is one of the few that have actually measured the cadmium burden in the general population in order to study its association with the risk of prostate cancer. Recall bias in terms of multiple items of risk exposure was minimal. Since not all subjects donated specimens for cadmium determination, it is possible that differences in cadmium burden exist between specimen donors and non-donors. However, this bias may also be minimal because the smoking rates and socio-demographic parameters (such as education level) were similar among donors and non-donors. The other strength is that this is the first study to have associated cadmium exposure with the stage and Gleason score of the disease. This interesting relationship between prostate cancer phenotypes and cadmium levels may be due to an effect of specific tumor type and not to an etiological role of the metal.

\section{Conclusion}

This study provides new information regarding the nonoccupational cadmium exposure and the development of prostate cancer. The cadmium level might be an indicator of the progress of the disease, greater level in the more advanced stage. Little evidence can be advanced to prove that cadmium is a predictor of prostate cancer. Further studies to clarify the pathways of cadmium metabolism in the prostate and the genetic susceptibility that interacts with cadmium may help in the understanding of cadmium-mediated prostate carcinogenesis.

\section{List of abbreviations}

CAUCd: creatinine-adjusted urinary cadmium level; UCd: Urine cadmium level; BCd: blood cadmium level; OR: odds ratio; $\mathrm{CI}$ : confidence interval.

\section{Competing interests}

The authors declare that they have no competing interests.

\section{Authors' contributions}

FS is the PI who initiated the study design, and carried out this study. YPu, HW, TW and ML recruited subjects and conducted diagnosis. YC and YPu carried out laboratory work and initiated manuscript development. CY participated in the study design and data interpretation. All authors participated in the conception and design of the study, and in the writing and approval of the manuscript.

\section{Acknowledgements}

This study received support from Executive Yuan National Science Council grant number NSC 89-2320-B-002-122. We thank those who assisted with 
patient recruitment at Taipei Veterans General Hospital, National Taiwan University Hospital, China Medical University Hospital, and Kaohsiung Veterans General Hospital. YC Chen and YS Pu are co-first authors.

\section{References}

I. Pu YS: Prostate cancer in Taiwan: epidemiology and risk factors. Int J Andrl 2000, 23(Suppl 2):34-6.

2. Giovannucci E, Rimm EB, Colditz GA, Stampfer MJ, Ascherio A, Chute CC, Willett WC: A prospective study of dietary fat and risk of prostate cancer. I Natl Cancer Inst 1993, 85: I57I-9.

3. Whittemore AS, Kolonel LN, Wu AH, John EM, Gallagher RP, Howe GR, Burch JD, Hankin J, Dreon DM, West DW, The CZ, Paffenbarger RS Jr: Prostate cancer in relation to diet, physical activity, and body size in blacks, whites, and Asians in the United States and Canada. J Natl Cancer Inst 1995, 87:652-6I.

4. Potts CL: Cadmium proteinuria-the health of battery workers exposed to cadmium oxide dust. Ann Occup Hyg 1965, 8:55-6I.

5. Armstrong BG, Kazantzis G: Prostatic cancer and chronic respiratory and renal disease in British cadmium workers: a case control study. Br J Ind Med 1985, 42:540-5.

6. Aronson KJ, Siemiatycki J, Dewar R, Gerin M: Occupational risk factors for prostate cancer: results from a case-control study in Montreal, Quebec, Canada. Am J Epidemiol 1996, I43:363-73.

7. Bako G, Smith ES, Hanson J, Dewar R: The geographical distribution of high cadmium concentrations in the environment and prostate cancer in Alberta. Can J Public Health 1982, 73:92-4.

8. Kolonel L, Winkelstein W Jr: Cadmium and prostatic carcinoma. Lancet 1997, 2:566-7.

9. Garcia Sanchez A, Antona JF, Urrutia M: Geochemical prospection of cadmium in a high incidence area of prostate cancer, Sierra de Gata, Salamanca, Spain. Sci Total Environ 1992, I I 6:243-5I.

10. Boffetta P: Methodological aspects of the epidemiological association between cadmium and cancer in humans. In Cadmium in the Human Environment: Toxicity and Carcinogenicity Edited by: Nordberg GF, Herber RF, Alessio L. Lyon, France: International Agency for Research on Cancer; 1992:425-434.

II. Sahmoun AE, Case LD, Jackson SA, Schwartz GG: Cadmium and cancer: a critical epidemiologic analysis. Cancer Invest 2005, 23:256-63.

12. Feustel A, Wennrich R, Steiniger D, Klauss P: Zinc and cadmium concentration in prostatic carcinoma of different histological grading in comparison to normal prostate tissue and adenofibromyomatosis (BPH). Urol Res 1982, 10:301-3.

13. Vinceti M, Venturelli M, Sighinolfi Chiara, Trerotoli Paolo, Bonvicini F, Ferrari A, Bianchi G, Serio G, Bergomi M, Vivoli G: Case-control study of toenail cadmium and prostate cancer risk in Italy. Sci Total Environ 2007, 373:77-81.

14. Chen YC, Lin RS, Pu YS, Chiang Cl, Lai MK, Sung JFC: Diet, vegetarian food and prostate cancer in Taiwan. Brit J Cancer 2005, 93: $1057-6 \mid$.

15. Sung JF, Lin RS, Pu YS, Chen YC, Chang HC, Lai MK: Risk factors for prostate carcinoma in Taiwan: a case-control study in a Chinese population. Cancer 1999, 86:484-91.

16. Lauwerys RR, Bernard A, Roels HA, Buchet JP, Viau C: Characterization of cadmium proteinuria in man and rat. Environ Health Perspect 1984, 54:147-52.

17. Lauwerys RR, Bernard AM, Roels HA, Buchet JP: Cadmium: exposure markers as predictors of nephrotoxic effects. Clin Chem 1994, 40:139|-4.

18. Lee JS, White KL: A review of the health effects of cadmium. Am J Ind Med 1980, I:307-I7.

19. Waalkes MP, Rehm S, Riggs CW, Bare RM, Devor DE, Poirier LA, Wenk ML, Henneman JR, Balaschak MS: Cadmium carcinogenesis in male Wistar [Crl:(WI)BR] rats: dose-response analysis of tumor induction in the prostate and testes and at the injection site. Cancer Res 1988, 48:4656-63.

20. van Wijngaarden E, Singer EA, Palapattu GS: Prostate-specific antigen levels in relation to cadmium exposure and zinc intake: results from the 200I-2002 National Health and Nutrition Examination Survey. Prostate 2008, 68:122-128.

21. Ogunlewe JO, Osegbe DN: Zinc and cadmium concentrations in indigenous blacks with normal, hypertrophic, and malignant prostate. Cancer 1989, 63:1388-92.
22. Sharma RP, McKenzie JM, Kjellstrom T: Analysis of submicrogramme levels of cadmium in whole blood, urine and hair by graphite furnace atomic absorption spectroscopy. J Anal Toxicol 1982, 6: I35-8.

23. Kjellstrom T: Mechanism and epidemiology of bone effects of cadmium. IARC Sci Publ 1992, I I 8:301-10.

24. Mueller PW, Smith SJ, Steinberg KK, Thun MJ: Chronic renal tubular effects in relation to urine cadmium levels. Nephron 1989, 52:45-54.

25. Roels HA, Lauwerys RR, Buchet JP, Bernard A, Chettle DR, Harvey $\mathrm{TC}, \mathrm{Al}-\mathrm{Haddad} \mathrm{IK}$ : In vivo measurement of liver and kidney cadmium in workers exposed to this metal: its significance with respect to cadmium in blood and urine. Environ Res 1981, 26:2 17-40.

26. Waalkes MP, Coogan TP, Barter RA: Toxicological principles of metal carcinogenesis with special emphasis on cadmium. Crit Rev Toxicol 1992, 22: 175-201.

27. Roels HA, Van Assche FJ, Oversteyns M, De Groof M, Lauwerys RR, Lison D: Reversibility of microproteinuria in cadmium workers with incipient tubular dysfunction after reduction of exposure. Am J Ind Med 1997, 3 I:645-52.

28. Feustel A, Wennrich R: Zinc and cadmium in cell fractions of prostatic cancer tissues of different histological grading in comparison to BPH and normal prostate. Urol Res 1984, I 2:147-50.

29. Klaassen CD: Cadmium. In Casarett \& Doull's Toxicology: the Basic Science of Poisons 5 th edition. Edited by: Klaassen CD, Amdur MO, Doull J. USA: McGraw-Hill; 1996:699-702.

\section{Pre-publication history}

The pre-publication history for this paper can be accessed here:

http://www.biomedcentral.com/1471-2407/9/429/prepub

Publish with Bio Med Central and every scientist can read your work free of charge

"BioMed Central will be the most significant development for disseminating the results of biomedical research in our lifetime. "

Sir Paul Nurse, Cancer Research UK

Your research papers will be:

- available free of charge to the entire biomedical community

- peer reviewed and published immediately upon acceptance

- cited in PubMed and archived on PubMed Central

- yours - you keep the copyright

Submit your manuscript here:

http://www.biomedcentral.com/info/publishing_adv.asp
BiolMedcentral 